Original Research Paper

\title{
Production of Al based Composites Reinforced with FeAl Intermetallic Particles by Mechanical Alloying
}

\author{
${ }^{1}$ Sergio Rubén Gonzaga Segura, ${ }^{1}$ Arturo Molina Ocampo, ${ }^{2}$ René Guardián Tapia and ${ }^{1}$ Alejandro Sedano Aguilar \\ ${ }^{1}$ Metalurgia de Polvos, Centro de Investigación en Ingeniería y Ciencias Aplicadas, Mexico \\ ${ }^{2}$ Caracterización de Materiales, Centro de Investigación en Ingeniería y Ciencias Aplicadas, Mexico
}

\author{
Article history \\ Received: 20-11-2020 \\ Revised: 11-02-2021 \\ Accepted: 11-03-2021 \\ Corresponding Author: \\ Arturo Molina Ocampo \\ Metalurgia de Polvos, Centro \\ de Investigación en Ingeniería y \\ Ciencias Aplicadas, Mexico \\ Email: arturo_molina@uaem.mx
}

\begin{abstract}
In this research project, Al matrix composite materials reinforced with 5 and 10 (wt. \%) of FeAl intermetallic particles were synthesized by Mechanical Alloying (MA) at a speed of 250 RPM for 2, 5, 10 and $15 \mathrm{~h}$ of milling time. The results showed that composite materials can be obtained at low energy conditions with improved dispersion of the reinforcement in the Al matrix compared to those obtained by conventional techniques. The composites powders obtained by mechanical alloying at different milling times were studied by Scanning Electron Microscopy (SEM) in order to characterize the morphology and particle size. X-Ray Diffraction (XRD) was used to study the structural evolution of the system as the initial powders were subjected to different milling times, thus obtaining the evolution of the present phases, changes in lattice parameters and crystallite size. This study demonstrates the viability of the MA technique to produce composite materials with a homogenous distribution of the reinforcement particles with a great degree of control in the process, which would be very difficult to reproduce by conventional synthesis methods.
\end{abstract}

Keywords: Mechanical Alloying, Aluminum Composites, Powder Metallurgy, Intermetallic

\section{Introduction}

Aluminum is one of the most used materials in today's industry due to its low weight, malleability and corrosion resistance (Khakbiz and Akhlaghi, 2009), it is also one of the most abundant materials available in nature. But, its strength, stiffness and low mechanical properties at high temperatures, excludes its usability from some high performance applications (Sadeghian et al., 2011). Recent studies have succeeded in improving the mechanical properties of aluminum through the dispersion of ceramic particles and oxides in an aluminum matrix (Sadeghian et al., 2011) by mechanical milling.

Mechanical Alloying (MA) is a unique solid state reaction process that develops between the surface of the powders at room temperature, consequently, it can be used to synthesize alloys impossible or difficult to obtain by conventional methods, all this due to its uniqueness to process new materials. The mechanical alloying process has attracted a lot of attention and inspired numerous investigations due to its promising results. With respect to composite materials, the mechanical alloying technique is capable of producing powders with a superior homogeneity compared to other methods
(Suryanarayana et al., 2001). Furthermore, it has been proved to be very effective to disperse the reinforcement phase in the matrix while promoting a very fine grain size ideal for improving the mechanical properties of the composite materials (Gilman and Benjamin, 1983). The mechanical alloying process consists in a mixture of powders placed in a container and subjected to highenergy collisions by the balls over a period of time to reach conditions where welding and fracture events become stable, another of the attributes of the MA technique is that it allows the extension of solubility limits of the alloys, thus achieving supersaturated solid solutions with improved mechanical properties.

On the other hand, intermetallic compounds have emerged as one of the most promising materials for engineering applications due to their high Young's module, hardness, mechanical strength and corrosion resistance (Shuai et al., 2021). Additionally, FeAl intermetallics have attracted much attention due to its resistance to high temperatures (Grosdidier et al., 2006; Godlewska et al., 2003; Martinez et al., 2006), being low-cost materials with a relatively low density $\left(5.56 \mathrm{~g} / \mathrm{cm}^{3}\right)$ as well as exhibiting good mechanical properties and excellent corrosion resistance in oxidizing 
atmospheres and sulfurators (Sikka et al., 1992; Koch, 1998; Mitchell et al., 2002; Stoloff, 1998). Higher percentages of $\mathrm{Al}$ in $\mathrm{FeAl}$ intermetallics have been shown to reduce ductility (Deevi and Sikka, 1996; Cohron et al., 1998). Recent studies have demonstrated the feasibility of manufacturing $\mathrm{FeAl}$ intermetallics by advance Powder Metallurgy (PM) methods, such as hot isostatic pressing (Skoglund et al., 2004), extrusion (Morris and Gunther, 1996; Chao et al., 2001), hot forging or pressing (Morris-Munoz et al., 1999; Krasnowski and Kulik, 2007) and molding by powder injection (Kato and Masui, 2002).

Until now there is a limited amount of information available regarding the synthesis of $\mathrm{Al}$ based composites reinforced with FeAl intermetallic particles, this makes their synthesis highly relevant in the MA research field, since the employed processing parameters give the possibility to control the precipitation of second phases, the microstructure of the obtained material and the distribution of the intermetallic particles. The purpose of this study is to investigate the effects on the microstructural evolution of the FeAl particles in the $\mathrm{Al}$ matrix obtained by mechanical alloying technique under low energy milling conditions.

\section{Materials and Methods}

Al matrix powders reinforced with 5 and 10 (wt. \%) of FeAl intermetallic particles were synthesized by MA in a planetary ball mill (pulverisette) by subjecting them to a milling time of $15 \mathrm{~h}$ at a speed of $250 \mathrm{rpm}$ using $10 \mathrm{~mm}$ diameter balls, with a ball to powder ratio of 10:1. The initial powders (Fig. 1) were weighted and encapsulated in stainless steel vials under an argon atmosphere with methyl alcohol $\left(\mathrm{CH}_{4} \mathrm{O}\right)$ as a Process Control Agent (PCA). XRD and SEM analysis were obtained for the samples of $\mathrm{Al}-5 \% \mathrm{FeAl}$ and $\mathrm{Al}-10 \% \mathrm{FeAl}$ after 2, 5, 10 and $15 \mathrm{~h}$ of milling. The final milled powders were cold compacted and sintered at an optimized temperature of 500 for $3 \mathrm{~h}$ in an argon atmosphere and subsequently, underwent Vickers microhardness testing with a load of $10 \mathrm{~g}$ in a Shimadzu micro hardness tester. The average crystallite size was obtained from Scherrer's equation (Eq. 1) in function of milling time:

$$
L=\frac{K \lambda}{B \cos \theta}
$$

where:

$L=$ The size of crystallite

$K=$ The proportionality constant (0.9)

$\lambda=$ The $\mathrm{X}$-ray wavelength $(0.1518$ nanometers for copper radiation)

$B=$ The peak width

$\theta=$ The diffraction angle
Lattice parameter for the synthesized samples were calculated from the Bragg's Law (Eq. 2):

$d=\frac{n \lambda}{2 \sin \theta}$

where:

$d=$ The interplanar spacing

$n=1$

$\lambda=$ The wavelength of the $\mathrm{x}$-rays

$\theta=$ The Bragg angle

\section{Results and Discussion}

Figure 1 shows the initial powders morphology and particle size. Scanning electron micrographs show a predominant spherical and lamellar shape morphology for $\mathrm{Al}$ powders meanwhile the FeAl intermetallic powders exhibit an irregular morphology (Table 1).

The micrograph of the mixture of $\mathrm{Al}-5 \% \mathrm{FeAl}$ powders after $2 \mathrm{~h}$ of milling (Fig. 2a) shows two types of deformation mechanisms typical of mechanical alloying; ductile deformation, which forms flatter and elongated particles, characteristic of the deformation that the $\mathrm{Al}$ powders experience during the first hours of milling and brittle deformation, which gives rise to the formation of particles with more angular and irregular morphology, which is typical of brittle materials such as intermetallic composites, ductile deformation has been reported by (Abdoli et al., 2008), to be the primary deformation mechanism responsible for the formation of larger particles during the MA process. Figure $2 \mathrm{~b}$ shows the decrease in the size of the particles and the absence of particles with angular morphology, which is a good indicator of the ductile deformation of the powders as the dominating phenomenon during the current stage of the MA process. However, the presence of large and small conglomerates can be an indication of fracture processes taking place, which are the result of work hardening exhibited by milled powders due to the accumulation of dislocations during the collisions with the balls. This behavior is similar to that reported by (Abdoli et al., 2008), who produced an Al-based composite material by mechanical milling. After $10 \mathrm{~h}$ of milling (Fig. 2c), the mixture of $\mathrm{Al}-5 \% \mathrm{FeAl}$ powders originated conglomerates as a result of a two-stage process, in the first stage, the ductile spherical Al particles are deformed to adopt a flat flakes morphology and during the second stage, these flat flakes are welded together to give rise to the formation of conglomerates. For the mixture of powders subjected to $15 \mathrm{~h}$ of milling (Fig. 2d), it can be observed that the particle size shows a decrease as well as a predominant irregular morphology, indicating that brittle fractures are the primary events occurring during this stage of milling, this is due to the strain hardening 
sustained by the powder particles. Figure 4a shows the variation in particle size decreases approximately from 25 to $10 \mu \mathrm{m}$ as the milling time has elapsed from 2 to $15 \mathrm{~h}$.

In the scanning electron micrographs shown in Fig. 3, it can be observed that the morphology of the particles underwent a polygonal and flake change to acquire an irregular shape as the milling time progresses. Particularly, Fig. 3a shows that at an early stage, the Al-10\% FeAl powders experienced ductile deformation, so large conglomerates are formed, this statement is consistent with what has been reported by (Suryanarayana et al., 2001) in the case of ductile-brittle systems. The mixture of $\mathrm{Al}-10 \% \mathrm{FeAl}$ powders after $10 \mathrm{~h}$ of milling is shown in Fig. 3c, in this micrograph, larger conglomerates are present, probably caused by the low energy supplied by the milling system mechanics. In the Fig. $3 \mathrm{~d}$ it can be seen that after $15 \mathrm{~h}$ of milling, there was a decrease in the amount of larger conglomerates, this due to the cold work hardening phenomenon of the mechanical alloying process, which causes that in the metal-intermetallic system, the fracture of particles begins to be more dominant than cold welding at the late stages of milling, this is due to the particles being hardened by mechanical work, which leads to fragmentation of the particles. The variation in the average particle size decreases approximately from 30 to $15 \mu \mathrm{m}$ as the milling time has elapsed from 2 to $15 \mathrm{~h}$ (Fig. $4 \mathrm{~b}$ ).

\section{$X$-Ray Diffraction}

In the X-ray diffraction patterns at different milling times Fig. 5 and 6 , it can be seen that for both compositions, the FeAl peaks are very small in intensity for every stage of milling, prevailing even after $15 \mathrm{~h}$ of milling, although a decrease in intensity and tip flattening is observed, which is associated to an amorphization process of the intermetallic phase. With regards to the intermetallic phase, it seems to indicate that there is not a diffusion process taking place, which indicates an ideal behavior for composite synthesis and dispersion of reinforcement particles in the Al matrix. Amorphization in ordered alloys seems to follow the following sequence (Jang and Koch, 1990).

Ordered phase $\Rightarrow$ Disordered phase (loss of long-range order) $\Rightarrow$ Crystallite size reduction $\Rightarrow$ Amorphous phase.

\section{Crystallite Size}

The average crystallite size as a function of the milling time corresponding to the Al-5\% FeAl and Al-10\% FeAl compositions are shown in Fig. 7, in the Al-5\%FeAl composite shows the crystallite has decreased slightly from 39.4 to $31.32 \mathrm{~nm}$ and for the composite $\mathrm{Al}-10 \% \mathrm{FeAl}$ decreased from 39.4 to $32.1 \mathrm{~nm}$ when subjected to a milling time of $15 \mathrm{~h}$. This decrease in nanometric grain size is associated with the low energy provided by the milling parameters (250 RPM). These results are consistent with those reported by (Rivera et al., 2012), who produced a composite material of Al-2024 matrix reinforced with $\mathrm{Al}_{2} \mathrm{O}_{3}$ particles by mechanical alloying from elemental $\mathrm{Al}, \mathrm{Cu}$ and $\mathrm{Mg}$ initial powders mixed with $\mathrm{Al}_{2} \mathrm{O}_{3}$ nano particles as a reinforcement phase. The authors reported that both the sample without Al-2024 reinforcement and those reinforced with 1 and $2 \%$ by weight of $\mathrm{Al}_{2} \mathrm{O}_{3}$ exhibited a reduction in crystallite size from $320 \mathrm{~nm}$ to approximately $50 \mathrm{~nm}$.

Table 1: Initial powders size and morphology

\begin{tabular}{lcc}
\hline Initial powders & Average particle size & Particle morphology \\
\hline $\mathrm{Al}$ & $4 \mu \mathrm{m}$ & Spherical and lamellar \\
$\mathrm{FeAl}$ & $12 \mu \mathrm{m}$ & Irregular \\
\hline
\end{tabular}
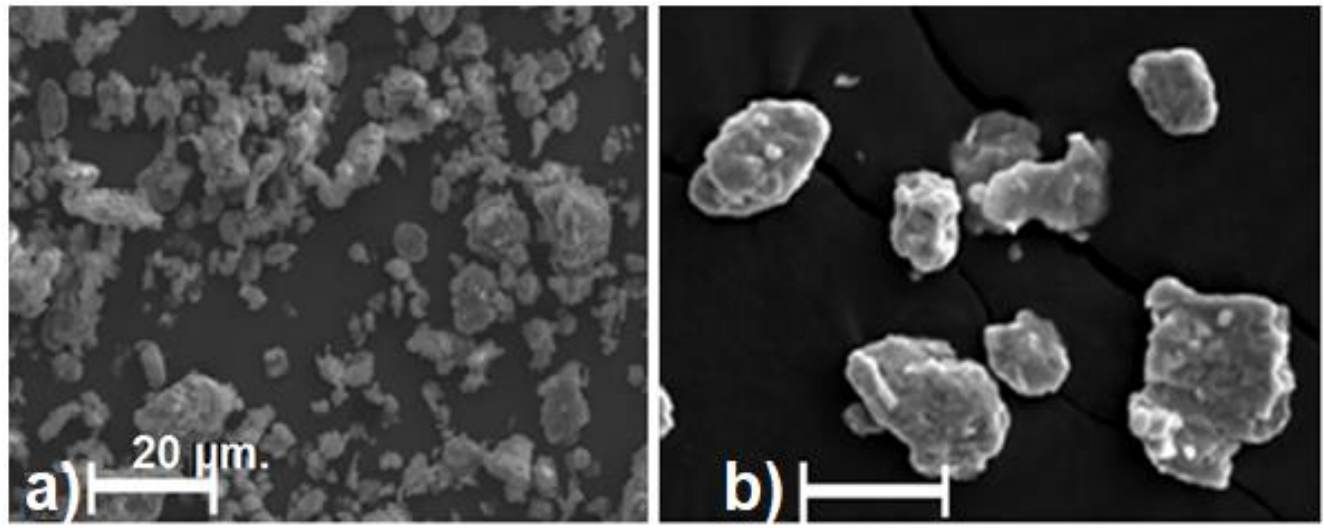

Fig. 1: SEM micrographs of the initial powders (a) Al and (b) FeAl 
Sergio Rubén Gonzaga Segura et al. / American Journal of Applied Sciences 2021, Volume 18: 61.70
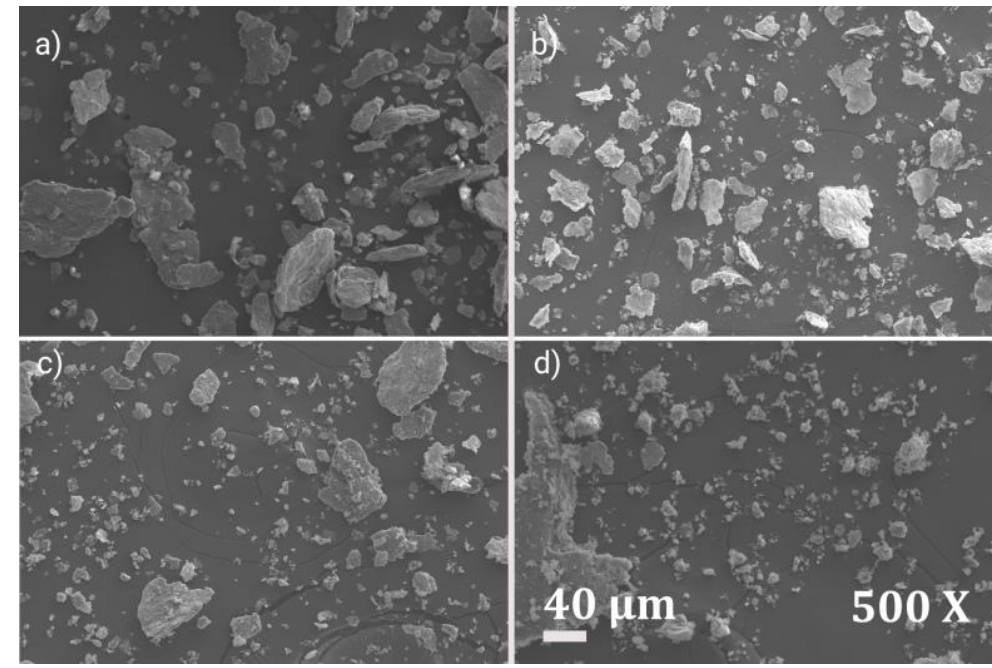

Fig. 2: SEM micrographs of the Al-5\% FeAl after (a) 2, (b) 5, (c) 10 and (d) $15 \mathrm{~h}$ of milling time

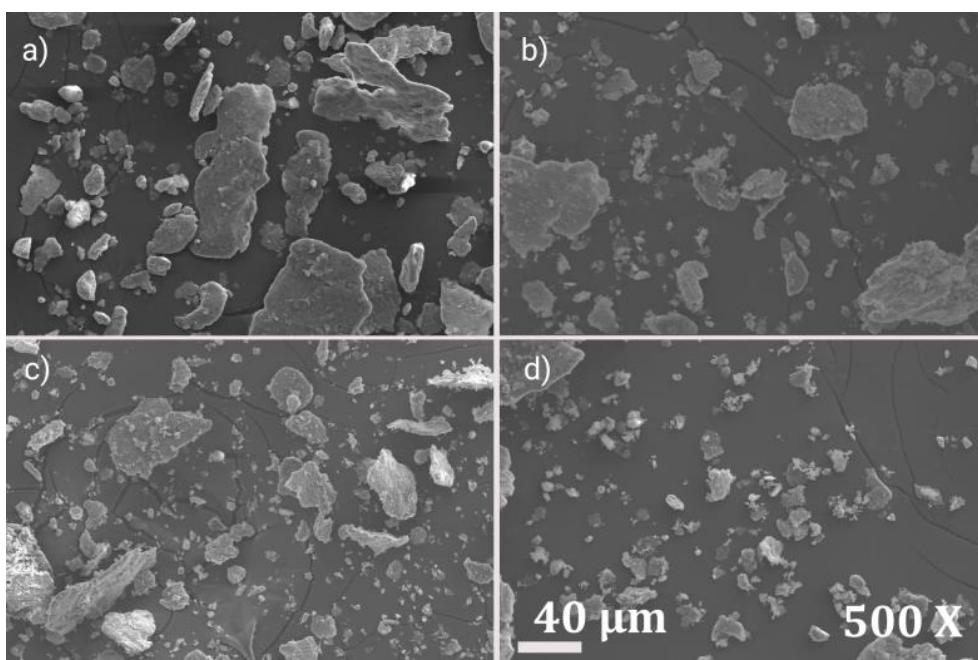

Fig. 3: SEM micrographs of the Al-10\% FeAl after (a) 2, (b) 5, (c) 10 and (d) $15 \mathrm{~h}$ of milling time a)

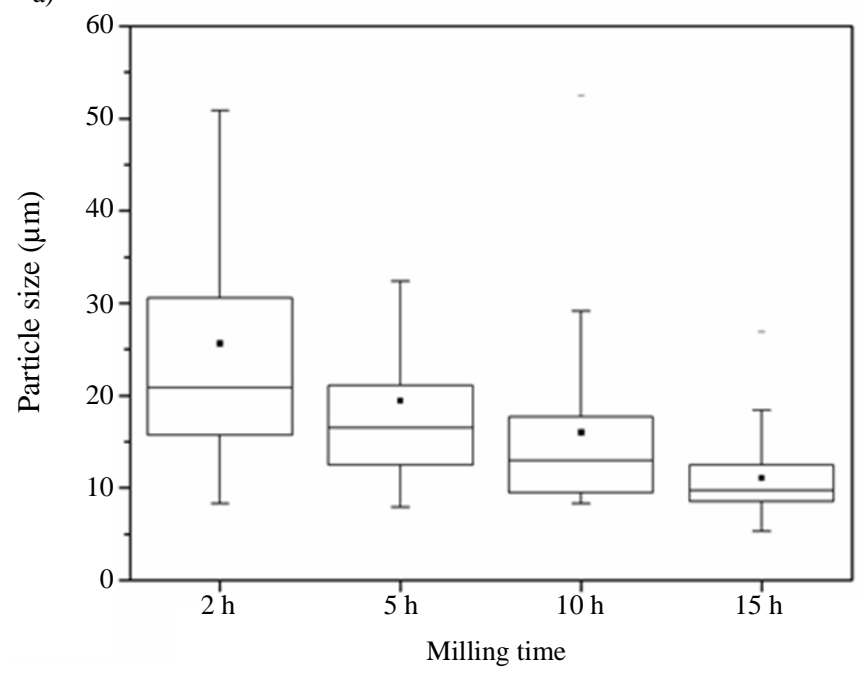


Sergio Rubén Gonzaga Segura et al. / American Journal of Applied Sciences 2021, Volume 18: 61.70 DOI: 10.3844/ajassp.2021.61.70

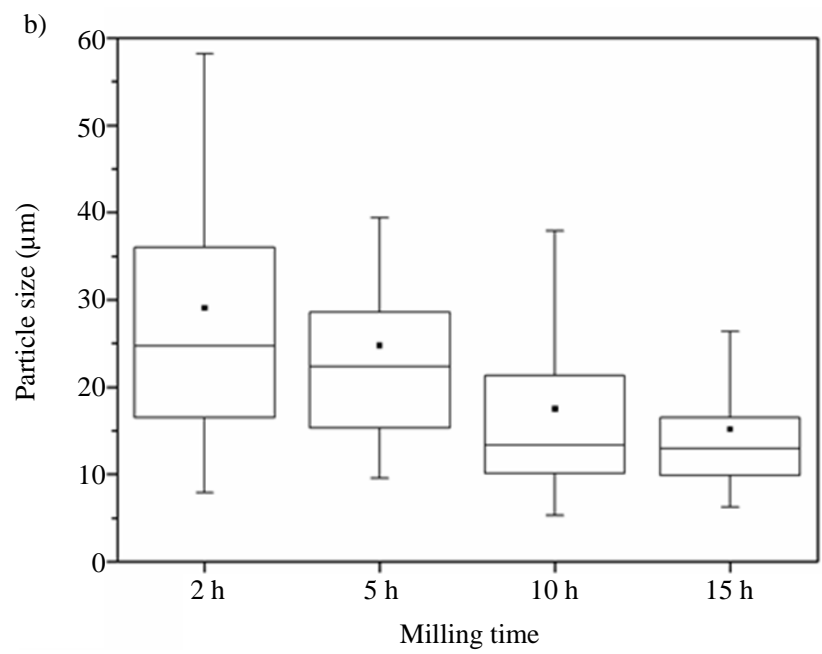

Fig. 4: Particle size evolution of the (a) Al-5\%FeAl and (b) Al-10\% FeAl during mechanical alloying

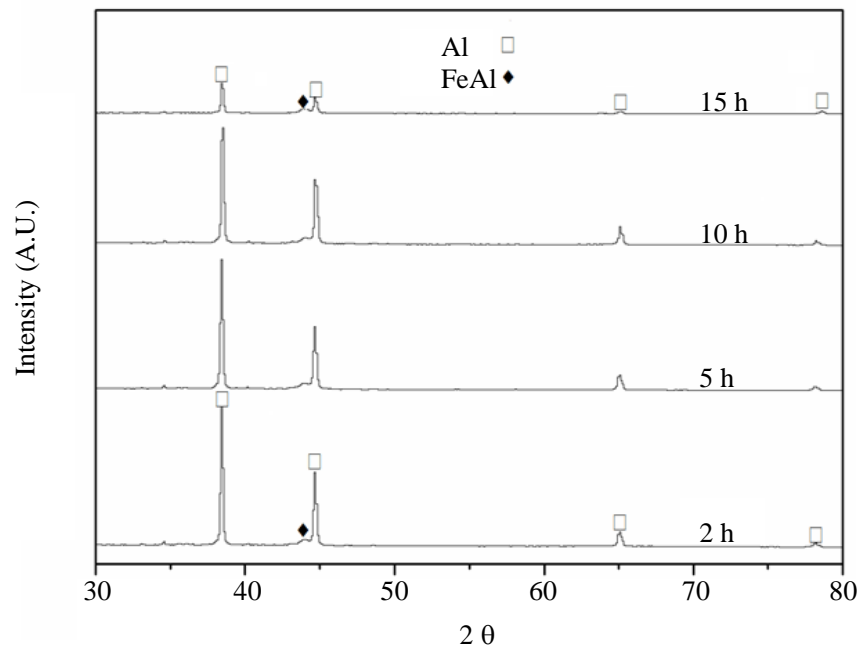

Fig. 5: XRD patterns of the Al-5\% FeAl powders during mechanical alloying

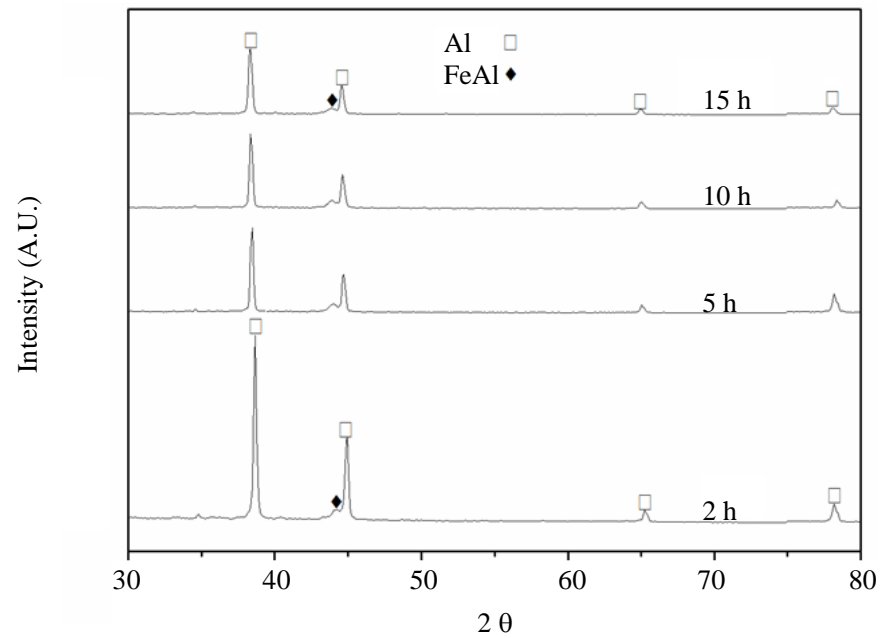

Fig. 6: XRD patterns of the $\mathrm{Al}-10 \% \mathrm{FeAl}$ powders during mechanical alloying 


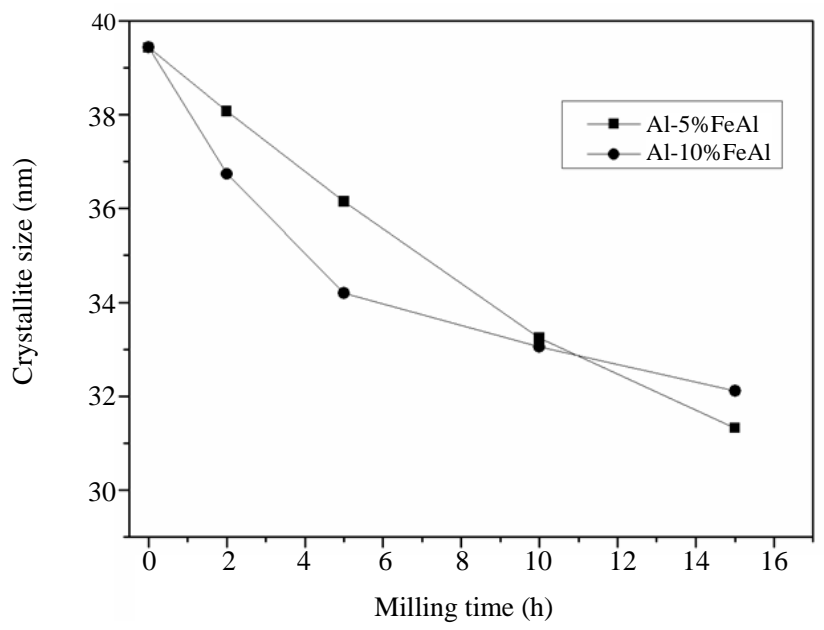

Fig. 7: Crystallite size during mechanical alloying of the $\mathrm{Al}-5 \% \mathrm{FeAl}$ and $\mathrm{Al}-10 \% \mathrm{FeAl}$

\section{Lattice Parameter}

Figure 8 shows the lattice parameter evolution during the milling process, it can be observed a tendency of being reduced as the milling time increases for both compositions. This reduction in the $\mathrm{Al}-5 \% \mathrm{FeAl}$ and $\mathrm{Al}-10 \% \mathrm{FeAl}$ lattice parameter has been demonstrated to be linked with the displacement of the XRD profile peaks and is usually linked to small contaminations of $\mathrm{Fe}$ from the stainless steel vials and balls. Resulting in the dissolution of contamination atoms in the Al matrix either interstitial, substitutional, or from multiple sources (Jacob et al., 2007). The almost linear initial behavior is congruent with the dissolution of a solute element according to Vegard's rule, but also an asymptotic behavior is observed, showing a saturation limit under such conditions. The results show a lattice parameter value for $\mathrm{Al}-5 \% \mathrm{FeAl}$ of $4.035 \AA$ and for $\mathrm{Al}-10 \% \mathrm{FeAl}$ of $4.045 \AA$ in $15 \mathrm{~h}$ milling time with an initial lattice parameter of $4.065 \AA$.

\section{Sintered Samples Analysis}

Multiple nanocomposites have been previously synthesized by the MA technique as well as by a subsequent low temperature processing of amorphous powders, resulting in their recrystallization and precipitation of second phases (Suryanarayana et al., 1993). An important benefit of these materials is the growth inhibition of the grain size. Figure 10 shows the XRD patterns of sintered $\mathrm{Al}-5 \% \mathrm{FeAl}$ and $\mathrm{Al}-10 \% \mathrm{FeAl}$ samples, it is observed that the peak corresponding to the FeAl phase increased in intensity and narrowed after the sintering process for both samples, this phenomenon is due to the recrystallization of the $\mathrm{FeAl}$ phase that previously underwent amorphization by the mechanical alloying process. Figure 9 shows the micrographs of the pure $\mathrm{Al}, \mathrm{Al}-5 \% \mathrm{FeAl}$ and $\mathrm{Al}-10 \% \mathrm{FeAl}$ cold compacted and sintered at $500^{\circ} \mathrm{C}$ for $3 \mathrm{~h}$. The microstructure of the pure $\mathrm{Al}$
(Fig. 9a) shows the presence of some grains of about $5 \mu \mathrm{m}$ that are produced during the sintering process. The sintered $\mathrm{Al}-5 \% \mathrm{FeAl}$ and $\mathrm{Al}-10 \% \mathrm{FeAl}$ samples (Fig. 9b and 9c), presented a good distribution and bonding between $\mathrm{Al}$ matrix and $\mathrm{FeAl}$ particles due to the combined effect of pressure and heat applied during the sintering process. The average size of the $\mathrm{FeAl}$ reinforcement for the $\mathrm{Al}-5 \% \mathrm{FeAl}$ composition is approximately $5 \mu \mathrm{m}$ and for $\mathrm{Al}-10 \% \mathrm{FeAl}$ is approximately $8 \mu \mathrm{m}$, the refinement of the size of the $\mathrm{FeAl}$ intermetallic particles is related to fractures that occur during the time of the mechanical alloying process.

\section{Microhardness Test}

As can be seen in Table 2, the composites of $\mathrm{Al}-5 \% \mathrm{FeAl}$ and $\mathrm{Al}-10 \% \mathrm{FeAl}$ showed a greater increase in microhardness compared to pure Al. The increase in the microhardness value of the composites were mainly attributed to the work hardening mechanism that occurred due to severe plastic deformation during uniaxial consolidation and the sintering process resulting in a stronger bond between reinforcement and matrix. In addition, as the milling time increased the dispersion of FeAl particles in the Al matrix is more homogeneous. In the micrographs sintered samples (Fig. 9), it can be observed a smaller size in the reinforcement particles for the $\mathrm{Al}-5 \% \mathrm{FeAl}$ sample than for the $\mathrm{Al}-10 \% \mathrm{FeAl}$ sample, which can be attributed to a greater increase in microhardness, confirming that reported by (Geng et al., 2018), that the increase in hardness of particles reinforced Al matrix compounds is related to the mechanical properties of reinforcing particles, but can be further improved by reducing the size and achieving an optimal dispersion of these particles in the aluminum matrix.

\section{General Discussion}

Scanning electron micrographs (Fig. 2 and 3) show the decrease in the size of the particles, which indicates 
that the ductile deformation mode is dominating the process. It can also be observed that the morphology of the particles underwent to acquire an irregular shape and a decrease in particle size as the milling time had advanced. The decrease of large conglomerates is due to the cold work hardening phenomenon of the mechanical alloying process, which leads to fragmentation of the particles. Song et al. (2009) reported a decrease in particle size with the course of milling time in an alloy Fe48Al (at. \%) mechanically alloying in a planetary mill at 303 RPM and with a ball to powder ratio of 10: 1 .

The lattice parameter evolution graph (Fig. 8), it can be observed a reduced as the milling time increases. This reduction is usually linked to small amounts of $\mathrm{Fe}$ released from the stainless steel vials and balls during the MA process.

The sintered samples (Fig. 9b and 9c) show the presence of FeAl particles in the matrix $\mathrm{Al}$ and although an amorphization process was observed in the XRD patterns, there wasn't evidence present that indicates a diffusion of the FeAl phase. This amorphization can be corroborated by the recrystallization process observed in the XRD patterns of the sintered samples (Fig. 10), in which there is a define $\mathrm{FeAl}$ peak with narrower high intensity $\mathrm{Al}$ peaks, this in turn is congruent with the recrystallization observed in the crystallite.

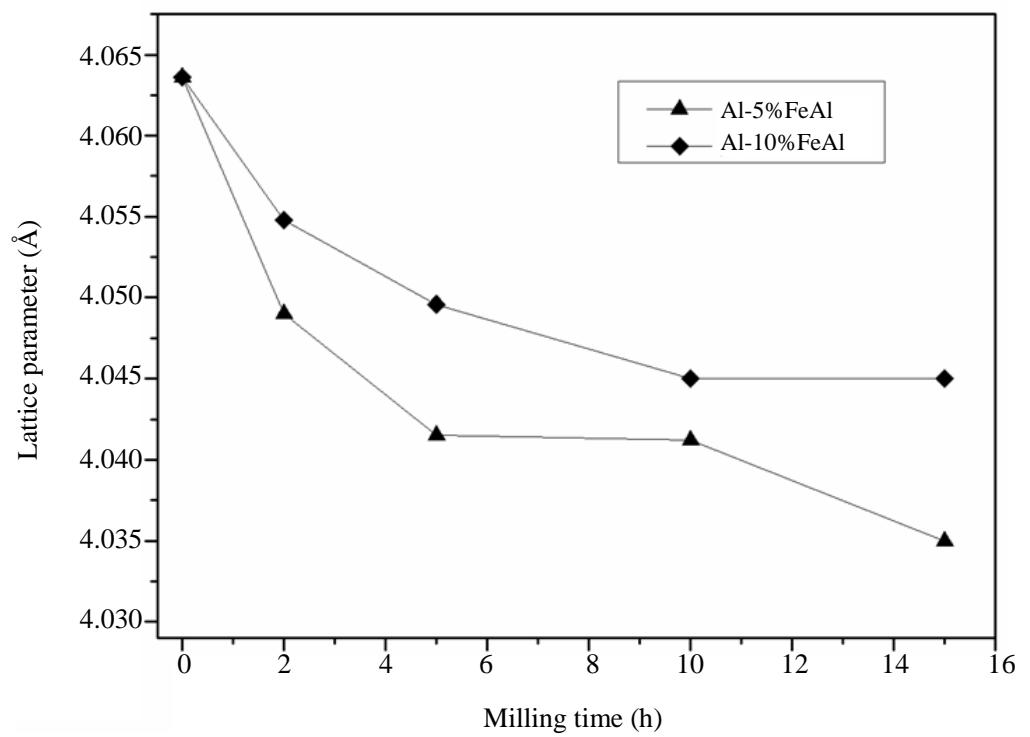

Fig. 8: Lattice parameter during mechanical alloying of the $\mathrm{Al}-5 \% \mathrm{FeAl}$ and $\mathrm{Al}-10 \% \mathrm{FeAl}$
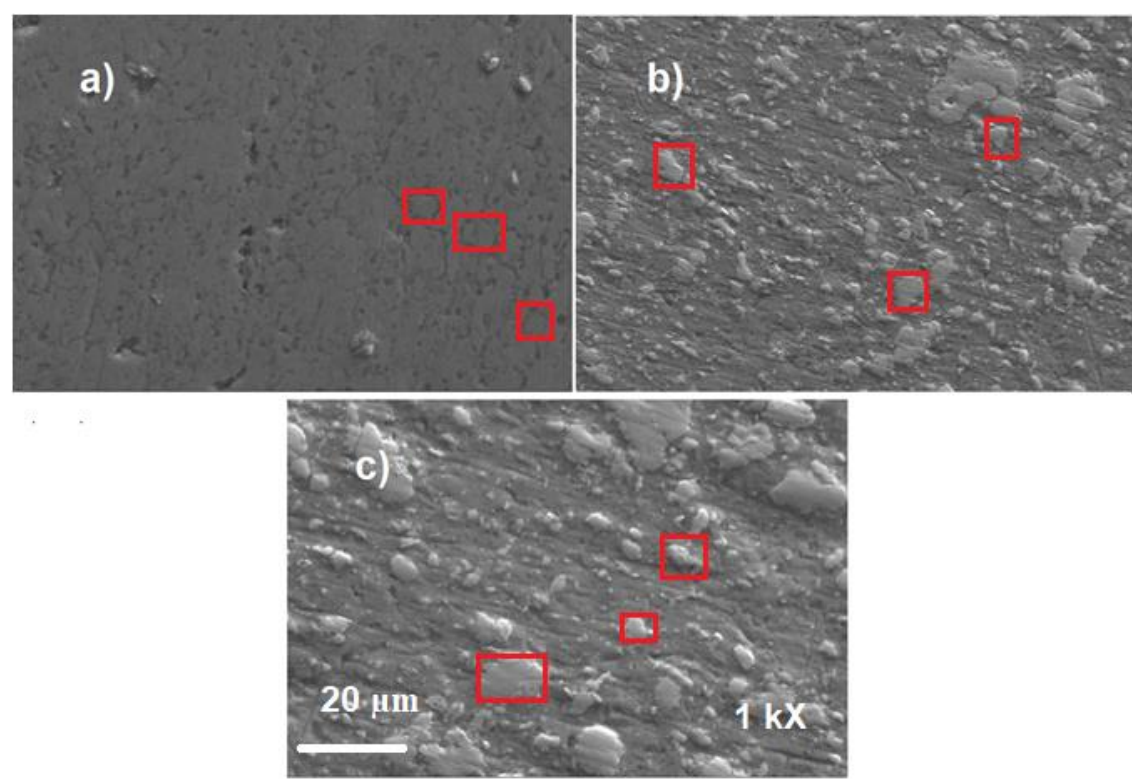

Fig. 9: SEM micrographs of the samples sintered (a) Al, (b) $\mathrm{Al}-5 \% \mathrm{FeAl}$ and (c) $\mathrm{Al}-10 \% \mathrm{Fe} A \mathrm{l}$ 


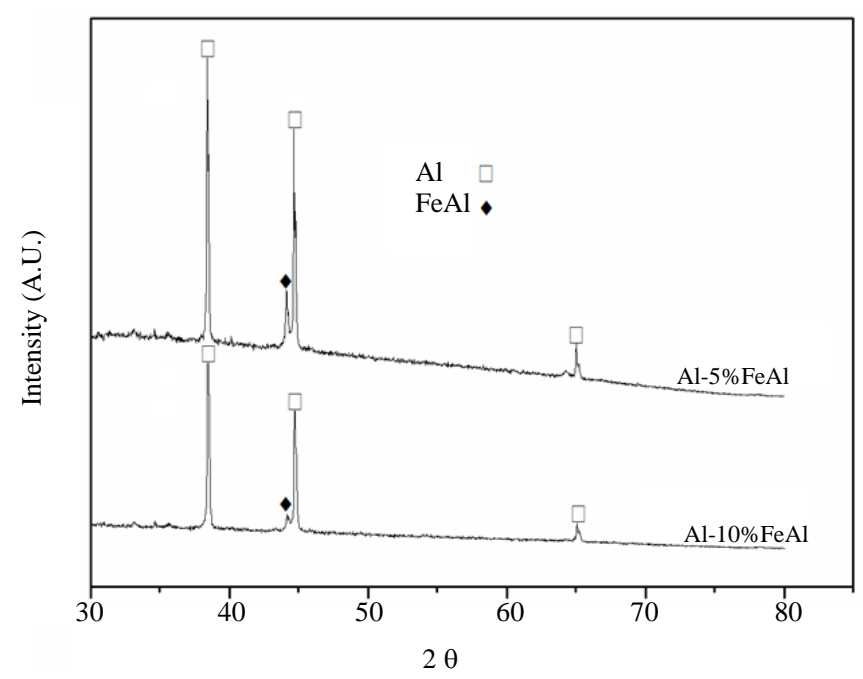

Fig. 10: XRD patterns of the samples sintered of $\mathrm{Al}-5 \% \mathrm{FeAl}$ and $\mathrm{Al}-10 \% \mathrm{FeAl}$

Table 2: Microhardness test results

\begin{tabular}{ll}
\hline Sample sintered & Microhardness (Hv) \\
\hline $\mathrm{Al}$ & 130.4 \\
$\mathrm{Fe}-5 \% \mathrm{FeAl}$ & 240.6 \\
$\mathrm{Fe}-10 \% \mathrm{FeAl}$ & 190.2 \\
\hline
\end{tabular}

Previous studies (Ganesh and Chawla, 2005) showed that the strength of the composites increases as the amount of the reinforcement increases. However, the results in this study are different from the previous studies. Since the results show that the Al-10\% FeAl sample shows lower hardness values than the $\mathrm{Al}-5 \% \mathrm{FeAl}$ sample, this can be attributed to the fact that the sample with higher reinforcement content could have generated greater porosity.

\section{Conclusion}

Al based composites with a composition 5 and 10 (wt. \%) of $\mathrm{FeAl}$ intermetallic particles were successfully synthesized using the mechanical alloying technique.

XRD and SEM analyses show that it is possible to synthesis Al based composite materials reinforced with intermetallic particles $\mathrm{FeAl}$ by mechanical alloying technique with low energy processing parameters that diminishes the possibility of diffusion process taking place between the reinforcement and the matrix.

The crystallite size shows a similar decrease in both compositions, going from 39.4 to $31.32 \mathrm{~nm}$ for $\mathrm{Al}-5 \% \mathrm{FeAl}$ and from 39.4 to $32.1 \mathrm{~nm}$ for $\mathrm{Al}-10 \% \mathrm{FeAl}$, this reduction in crystallite size is correlated to the refinement in particle size that was experienced during the mechanical milling process.

The lattice parameter shows a decrease in magnitude as the milling time elapsed, ranging from 4,065 to $4,035 \AA$ for $\mathrm{Al}-5 \% \mathrm{FeAl}$ composite and 4,065 to $4,045 \AA$ for
Al-10\% FeAl composite, this behavior is attributed to the contamination of Fe particles that were detached from the balls and vials during the mechanical alloying process.

The refinement process and homogenization of the reinforcement particles resulted in a noticeable increase in the hardness in the sintered samples. For $\mathrm{Al}-5 \% \mathrm{FeAl}$ composite, the hardness increased by $84 \%$ with respect to unreinforced Al samples, while for $\mathrm{Al}-10 \% \mathrm{FeAl}$ composite, the hardness increased by $45 \%$ with respect to the unreinforced Al samples. The hardness of the FeAl reinforcement and the diminishment in grain size by the dispersion of the reinforcement particles are the main factors involved.

This research demonstrates the possibility of improving properties and reduce the cost of synthesis of $\mathrm{Al}$ based composites reinforced with $\mathrm{FeAl}$ intermetallic particles through low energy mechanical alloying.

\section{Acknowledgment}

This study was financed by CONACyT [Grant Number 467318].

\section{Author's Contributions}

Sergio Rubén Gonzaga Segura: He designed the research plan, participated in all the experimental development of the dresearch, participated in the analysis of results and contributed to the writing of the paper.

Arturo Molina Ocampo: He designed the research plan, participated to the process of mechanical alloying and mechanical milling, participated in the analysis of results and contributed to the writing of the paper.

René Guardián Tapia: He performed the X-ray diffraction analysis and participated in the microstructural characterization of the alloys through 
electron microscopy techniques.

Alejandro Sedano Aguilar: He participated in the analysis and interpretation of resulus and contributed to the writing of the paper.

\section{Ethics}

This article is original and contains unpublished material. The corresponding author confirms that all of the other authors have read and approved the manuscript and no ethical issues involved.

\section{References}

Abdoli, H., Farnoush, H., Salahi, E., \& Pourazrang, K. (2008). Study of the densification of a nanostructured composite powder: Part 1: Effect of compaction pressure and reinforcement addition. Materials Science and Engineering: A, 486(1-2), 580-584. doi.org/10.1016/j.msea.2007.09.034

Chao, J., Morris, D. G., Muñoz-Morris, M. A., \& GonzálezCarrasco, J. L. (2001). The influence of some microstructural and test parameters on the tensile behaviour and the ductility of a mechanically-alloyed $\mathrm{Fe}-40 \mathrm{Al}$ alloy. Intermetallics, 9(4), 299-308. doi.org/10.1016/S0966-9795(01)00005-X

Cohron, J. W., Lin, Y., Zee, R. H., \& George, E. P. (1998). Room-temperature mechanical behavior of FeAl: Effects of stoichiometry, environment and boron addition. Acta Materialia, 46(17), 6245-6256. doi.org/10.1016/S1359-6454(98)00254-7

Deevi, S. C., \& Sikka, V. K. (1996). Nickel and iron aluminides: An overview on properties, processing and applications. Intermetallics, 4(5), 357-375. doi.org/10.1016/0966-9795(95)00056-9

Ganesh, V. V., \& Chawla, N. (2005). Effect of particle orientation anisotropy on the tensile behavior of metal matrix composites: Experiments and microstructure-based simulation. Materials Science and Engineering: $A, \quad 391(1-2), \quad 342-353$. doi.org/10.1016/j.msea.2004.09.017

Geng, R., Qiu, F., \& Jiang, Q. C. (2018). Reinforcement in Al Matrix Composites: A Review of Strengthening Behavior of Nano-Sized Particles. Advanced Engineering Materials, 20(9), 1701089. doi.org/10.1002/adem.201701089

Gilman, P. S., \& Benjamin, J. S. (1983). Mechanical alloying. Annual Review of Materials Science, 13(1), 279-300. doi.org/10.1146/annurev.ms.13.080183.001431

Godlewska, E., Szczepanik, S., Mania, R., Krawiarz, J., \& Kozinski, S. (2003). FeAl materials from intermetallic powders. Intermetallics, 11(4), 307-312. doi.org/10.1016/S0966-9795(02)00247-9
Grosdidier, T., Ji, G., Bernard, F., Gaffet, E., Munir, Z. A., \& Launois, S. (2006). Synthesis of bulk FeAl nanostructured materials by HVOF spray forming and spark plasma sintering. Intermetallics, 14(10-11), 1208-1213. doi.org/10.1016/j.intermet.2005.11.033

Jacob, K. T., Raj, S., \& Rannesh, L. (2007). Vegard's law: A fundamental relation or an approximation?. International Journal of Materials Research, 98(9), 776-779. doi.org/10.3139/146.101545

Jang, J. S. C., \& Koch, C. C. (1990). Amorphization and disordering of the Ni $3 \mathrm{Al}$ ordered intermetallic by mechanical milling. Journal of Materials Research, 5(3), 498-510. doi.org/10.1557/JMR.1990.0498

Kato, K., \& Masui, T. (2002). Influence of boron addition on the tensile properties of sintered FeAl compacts by powder injection molding. Journal of the Japan Society of Powder and Powder Metallurgy, 49(9), 787-792. doi.org/10.2497/jjspm.49.787

Khakbiz, M., \& Akhlaghi, F. (2009). Synthesis and structural characterization of Al-B4C nanocomposite powders by mechanical alloying. Journal of Alloys and Compounds, 479(1-2), 334-341. doi.org/10.1016/j.jallcom.2008.12.076

Koch, C. C. (1998). Intermetallic matrix composites prepared by mechanical alloying-a review. Materials Science and Engineering: A, 244(1), 39-48. doi.org/10.1016/S0921-5093(97)00824-1

Krasnowski, M., \& Kulik, T. (2007). Nanocrystalline FeAl intermetallic produced by mechanical alloying followed by hot-pressing consolidation. Intermetallics, 15(2), 201-205. doi.org/10.1016/j.intermet.2006.05.008

Martinez, M., Viguier, B., Maugis, P., \& Lacaze, J. (2006). Relation between composition, microstructure and oxidation in iron aluminides. Intermetallics, 14(10-11), 1214-1220. doi.org/10.1016/j.intermet.2005.11.018

Mitchell, T. E., Hirth, J. P., \& Misra, A. (2002). Apparent activation energy and stress exponent in materials with a high Peierls stress. Acta Materialia, 50(5), 1087-1093. doi.org/10.1016/S1359-6454(01)00409-8

Morris, D. G., \& Gunther, S. (1996). Strength and ductility of Fe 40Al alloy prepared by mechanical alloying. Materials Science and Engineering: A, 208(1), 7-19. doi.org/10.1016/0921-5093(95)10041-5

Morris-Munoz, M. A., Dodge, A., \& Morris, D. G. (1999). Structure, strength and toughness of nanocrystalline FeAl. Nanostructured Materials, 11(7), 873-885. doi.org/10.1016/S0965-9773(99)00385-2

Rivera, J. H., Rivera, J. C., Del Angel, V. P., Febles, V. G., Alonso, O. C., \& Martínez-Sánchez, R. (2012). Structural and morphological study of a 2024 Al$\mathrm{Al}_{2} \mathrm{O}_{3}$ composite produced by mechanical alloying in high energy mill. Materials \& Design, 37, 96-101. doi.org/10.1016/j.matdes.2011.12.035 
Sadeghian, Z., Lotfi, B., Enayati, M. H., \& Beiss, P. (2011). Microstructural and mechanical evaluation of Al-TiB2 nanostructured composite fabricated by mechanical alloying. Journal of Alloys and Compounds, 509(29), 7758-7763. doi.org/10.1016/j.jallcom.2011.04.145

Shuai, C., He, C., Peng, S., Qi, F., Wang, G., Min, A., ... \& Wang, W. (2021) Mechanical Alloying of Immiscible Metallic Systems: Process, Microstructure and Mechanism. Advanced Engineering Materials, 2001098. doi.org/10.1002/adem.202001098

Sikka, V. K., Mavity, J. T., \& Anderson, K. (1992). Processing of nickel aluminides and their industrial applications. In High Temperature Aluminides and Intermetallics (pp. 712-721). Elsevier. doi.org/10.1016/0921-5093(92)90276-7

Skoglund, H., Wedel, M. K., \& Karlsson, B. (2004). Processing of fine-grained mechanically alloyed FeAl. Intermetallics, 12(7-9), 977-983.

doi.org/10.1016/j.intermet.2004.03.004
Song, H., Wu, Y., Yuan, S., Gong, Q., \& Liang, J. (2009). Microstructure and mechanical properties of FeAl intermetallics prepared by mechanical alloying and hot-pressing. Tsinghua Science and Technology, 14(3), 300-306. doi.org/10.1016/S1007-0214(09)70044-6

Stoloff, N. S. (1998). Iron aluminides: Present status and future prospects. Materials Science and Engineering: A, 258(1-2), 1-14. doi.org/10.1016/S0921-5093(98)00909-5

Suryanarayana, C., Ivanov, E., \& Boldyrev, V. V. (2001). The science and technology of mechanical alloying. Materials Science and Engineering: A, 304, 151-158. doi.org/10.1016/S0921-5093(00)01465-9

Suryanarayana, C., Korth, G. E., Chen, G. H., Frefer, A., \& Froes, F. H. (1993). Thermal stability of nanostructured titanium aluminides. Nanostructured Materials, 2(5), 527-535. doi.org/10.1016/0965-9773(93)90170-G 